\title{
Preconsult interactive computer-assisted client assessment survey for common mental disorders in a community health centre: a randomized controlled trial
}

\author{
Farah Ahmad MBBS MPH PhD, Wendy Lou PhD, Yogendra Shakya PhD, Liane Ginsburg PhD, \\ Peggy T. Ng PhD, Meb Rashid MD, Serban Dinca-Panaitescu PhD, Cliff Ledwos MA, \\ Kwame McKenzie MD
}

\section{Abstract}

Background: Access disparities for mental health care exist for vulnerable ethnocultural and immigrant groups. Community health centres that serve these groups could be supported further by interactive, computer-based, self-assessments.

\begin{abstract}
Methods: An interactive computer-assisted client assessment survey (iCCAS) tool was developed for preconsult assessment of common mental disorders (using the Patient Health Questionnaire [PHQ-9], Generalized Anxiety Disorder 7-item [GAD-7] scale, Primary Care Post-traumatic Stress Disorder [PTSD-PC] screen and CAGE [concern/cut-down, anger, guilt and eye-opener] questionnaire), with point-of-care reports. The pilot randomized controlled trial recruited adult patients, fluent in English or Spanish, who were seeing a physician or nurse practitioner at the partnering community health centre in Toronto. Randomization into iCCAS or usual care was computer generated, and allocation was concealed in sequentially numbered, opaque envelopes that were opened after consent. The objectives were to examine the interventions' efficacy in improving mental health discussion (primary) and symptom detection (secondary). Data were collected by exit survey and chart review.
\end{abstract}

Results: Of the 1248 patients assessed, 190 were eligible for participation. Of these, 148 were randomly assigned (response rate $78 \%)$. The iCCAS $(n=75)$ and usual care $(n=72)$ groups were similar in sociodemographics; $98 \%$ were immigrants, and $68 \%$ were women. Mental health discussion occurred for $58.7 \%$ of patients in the iCCAS group and $40.3 \%$ in the usual care group ( $p \leq 0.05)$. The effect remained significant while controlling for potential covariates (language, sex, education, employment) in generalized linear mixed model (GLMM; adjusted odds ratio [OR] 2.2; 95\% confidence interval $[\mathrm{Cl}] 1.1-4.5)$. Mental health symptom detection occurred for $38.7 \%$ of patients in the iCCAS group and $27.8 \%$ in the usual care group $(p>0.05)$. The effect was not significant beyond potential covariates in GLMM (adjusted OR 1.9; 95\% Cl 0.9-4.1).

Interpretation: The studied intervention holds potential for community health centres to improve mental health discussion. Further research with larger samples should examine the impact on detection and enhance generalizability. Trial registration: ClinicalTrials.gov, no: NCT02023957, registered on Dec. 12, 2013.

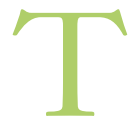
he World Health Organization predicts that common mental disorders such as depression will rank first in the burden of diseases for high-income countries by $2030 .{ }^{1}$ Depression can usually be effectively managed in primary care; however, most people with this illness in Canada do not get treatment. ${ }^{2}$ The rate of depression in patients visiting family practices is high $(14 \%-45 \%) ;{ }^{3-6}$ for this reason, maximizing its identification in primary care has been considered as a possible way of increasing the number of people receiving appropriate treatment. ${ }^{7,8}$

Ethnocultural and immigrant groups from non-European and low-income backgrounds in Canada are less likely to have their common mental disorders (such as depression, anxiety and post-traumatic stress disorder [PTSD]) treated than their peers ${ }^{9,10}$ because they often encounter multifold barriers to accessing timely care. ${ }^{10-13}$ The development of community

Competing interests: None declared.

This article has been peer reviewed.

Correspondence to: Farah Ahmad, farahmad@yorku.ca

CMAJ Open 2017. DOI:10.9778/cmajo.20160118 
health centres has been effective in decreasing barriers to care for physical health for vulnerable communities such as immigrant and ethnocultural groups in Ontario. ${ }^{14}$ Studies report that these patients visit emergency departments less frequently and receive higher preventive care and chronic disease management compared with patients enrolled in other primary care models. ${ }^{15-18}$ Despite these successes, community health centre resources are stretched owing to the complex and growing needs of the vulnerable communities they aim to serve. In such situations, mental health problems may be less likely to be identified than physical health issues.

Increasing the determination of common mental disorders in community health centres could be one way of decreasing disparities in mental health treatment for vulnerable ethnocultural and immigrant groups. A recent innovation in this regard is the development of interactive and user-friendly preconsult eHealth tools. These tools can be available in the waiting room and can be used to alleviate some patient barriers (e.g., knowledge gaps, stigma and communication difficulties) and provider constraints such as time..$^{19,20}$

We developed an interactive computer-assisted client assessment survey (iCCAS) tool in English and Spanish for common mental disorders. ${ }^{21-23}$ This study reports a randomized controlled trial (RCT) of the efficacy of the tool for improving discussion about mental health issues and detection of mental illness in an urban community health centre in Toronto.

\section{Methods}

The study protocol for the 2-arm pilot RCT was developed in collaboration with the partnering community health centre. We followed CONSORT guidelines for nonpharmacological interventions. ${ }^{24}$

\section{Study site}

The partnering community health centre, Access Alliance, is located in Toronto, where more than $50 \%$ of the residents are immigrants and most identify themselves as members of racialized communities. ${ }^{25}$ The 3 clinics of Access Alliance serve primarily immigrant, refugee and racialized ethnoracial communities who report English and Spanish as their top preferred languages. These clinics employed 4 family physicians and 5 nurse practitioners along with a multidisciplinary team at the time of study.

\section{Intervention}

The study intervention was a touch-screen iCCAS with validated screening scales for common mental disorders and was administered to patients in the waiting room. The tool produced individualized reports for patients and clinicians before the patient was seen by a family physician or nurse practitioner. Completion time ranged from 10 to 15 minutes. Data were encrypted and collected on a secure remote server. The research assistant printed the reports using a password protected web portal. The Patient Recommendation Sheet summarized the risks, provided information about community resources and made suggestions to seek the clinician's advice when a risk was reported. The clinician risk report was a 1-page summary of the health risks and included scores and symptoms of the assessed common mental disorders in addition to possible referral pathways.

The development of the intervention included several steps. First, a comprehensive literature review of tools for identifying common mental disorders was undertaken. Twenty questionnaires used to identify major depression, generalized anxiety, PTSD and alcohol abuse in community or primary care samples were assessed on length, reliability, validity and use in diverse groups. The final selection of tools aimed for brevity while maintaining coverage of different common mental disorders important to diverse populations and cross-cultural validity. The final 52-item survey included the Patient Health Questionnaire 9 (PHQ-9); ${ }^{26}$ Generalized Anxiety Disorder 7-item (GAD-7) scale; ${ }^{27}$ Primary Care Post-traumatic Stress Disorder (PTSD-PC) screen; ${ }^{28}$ and $\mathrm{CAGE}^{29}$ (concern/cut-down, anger, guilt and eye-opener) scale, in addition to items pertaining to the social determinants of health (e.g., education, English language ability, housing, financial means to meet daily needs, immigration status and social support). Further details are described elsewhere..$^{30,31}$

Final survey and report structures were determined with input from researchers and community partners of Access Alliance; the survey was translated to and back-translated from Spanish, and a usability pilot was conducted with 9 clinicians and patients.

\section{Participants and procedures}

All family physicians and nurse practitioners at the study sites were eligible to participate, and all provided informed written consent permitting recruitment of their patients. Before patient recruitment, the physicians and nurse practitioners received a workshop with field updates by a mental health expert (K.M.) on the 4 included common mental disorders. Blinding of clinicians was not possible owing to nature of the intervention.

Patient inclusion criteria were age at least 18 years, proficiency in English or Spanish and visiting a consenting clinician. Exclusion criteria were being accompanied by a family member for interpretation, being a new patient, feeling unwell (self-report) or research assistant's inability to offer details (e.g., privacy or comprehension issues).

Patient recruitment occurred November 2013 to May 2014. Three trained research assistants (2 bilingual) approached patients in the waiting room and applied eligibility criteria. Eligible and willing patients received the study details in a separate room and provided informed written consent. The consenting patients were then randomized into the intervention (iCCAS) or control (usual care) group using 1:1 allocation. The randomized allocation sequence was computer generated by an off-site biostatistician before recruitment and concealed using sequentially numbered, opaque envelopes. ${ }^{32}$ The envelopes were opened after consent, keeping patients and recruiters blind to the assignment. 
Before seeing the clinician, patients assigned to the iCCAS group completed the interactive survey using an iPad and received a printout of their tailored recommendation sheet. The Risk Report for clinicians was attached to each patient file before the consultation. Patients assigned to the control group continued to receive usual care with no health-risk assessments before the consultation. After the visit, patients in both groups completed an exit survey and received a resource list. At this time, all patients were asked whether they would like to see a counselor for issues covered in the study surveys.

\section{Outcomes and data collection}

The main outcomes were patient discussion (yes or no) on mental health and clinician detection (yes or no) of mental health symptoms. The former was measured by the exit survey and the latter by review of the medical charts (clinical notes section) for both groups. The mental health discussion could have been initiated by either patient or clinician. Patient sociodemographic and health care-related information were collected for both groups by the exit survey. The tool's acceptance and technological quality were assessed in the intervention group by including the Computerized Lifestyle Assessment scale ${ }^{33,34}$ for assessing perceived benefits, privacy barriers and interaction barriers on 5-point (disagree, not sure or agree) subscales, and 4 quality questions (easy or difficult) 35,36 in the exit survey. The review of electronic medical charts was completed using a data extraction form that was developed with the assistance of the clinic's information technology team and piloted before its use.

\section{Statistical analysis}

A total recruitment of 150 patients was planned for this pilot study, with mental health discussion as the primary outcome of interest. A sample size of 75 patients per group was based on an anticipated improvement of a $20 \%-25 \%$ increase in the patient discussion rate as a result of the intervention.

We examined internal consistency of PHQ-9, GAD-7, PC-PTSD and CAGE scales using Cronbach $\alpha$.

The sociodemographic characteristics of patients randomized to each of the 2 groups (iCCAS and control) were first compared using bivariate analyses, and subsequent analyses for health-related characteristics were performed; correlations within patients seen by the same medical staff (family physician or nurse practitioner) were accounted for in these analyses using the generalized linear mixed model (GLMM) approach. The associations between the 2 mental health outcomes (discussion and detection) and patient characteristics (sociodemographic and health-related) were examined in a similar manner. To evaluate the effectiveness of the intervention (iCCAS), while taking into account patient characteristics and patient correlations, multivariable analyses using GLMM were employed. The covariates of language, sex, education and employment were included in the multivariable analyses based on clinician investigators' input, literature review and statistical evidence; none of these variables had missing data. Statistical analyses were performed using SAS version 9.4 (SAS Institute) and SPSS version 22.

\section{Ethics approval}

Research ethics approval was obtained from York University (certificate no. e2013-291).

\section{Results}

The numbers of patients randomized and included in the final analyses are detailed in Figure 1. Of 1248 patients assessed, 190 were eligible to participate, and 148 of these were randomly assigned (response rate $77.9 \%$ ). Six patients were found ineligible during chart review and excluded subsequently as recommended by Fergusson and colleagues. ${ }^{37}$ One patient who felt unwell immediately after consent and provided no data was not included in the analysis. There were 76 patients in the intervention (iCCAS) group and 72 in the control (usual care) group. Patients in the iCCAS group reported "agreement" with the perceived benefits of the tool (mean \pm standard deviation $[\mathrm{SD}] 4.1 \pm 0.6$ ) and were "not sure" for the barriers to privacy $(2.6 \pm 0.8)$ and interaction $(2.8 \pm 0.9)$. More than $95 \%$ of participants found the technology easy to use.

Internal consistency of PHQ-9, GAD-7, PC-PTSD and CAGE scales were $0.86,0.89,0.75$ and 0.63 , respectively.

\section{Sociodemographics}

Overall, patient age ranged from 18 to 71 years (mean $37 \pm$ $1.0), 61.2 \%$ identified as female and $78.2 \%$ participated in the study in English. A total of $97.9 \%$ were immigrants, and the top 3 regions of birth were Latin America (33.3\%), South Asia (27.9\%) and Africa or the Middle East (16.3\%). There were no significant differences in the sociodemographic characteristics between the iCCAS and the usual care groups (Table 1 and Table 2).

\section{Outcomes by sociodemographics}

Mental health discussion occurred for 49.7\% (73/147) of patients. The discussion frequency was higher for Englishspeaking $(86.3 \%)$ than for Spanish-speaking $(13.7 \%)$ patients, $(p \leq 0.05)$. Patients who had a mental health discussion received mental health referral more often $(30.1 \%)$ than patients who did not have a discussion $(5.4 \%)(p \leq 0.001)$. None of the other sociodemographic or health-related variables were significantly associated with the mental health discussion. The secondary outcome of mental health detection occurred for $33.3 \%$ (49/147) of patients. The frequency of mental health detection was higher for English-speaking $(89.8 \%)$ than for Spanish-speaking $(10.2 \%)$ patients, $(p<$ $0.05)$. Mental health detection was more common for unemployed $(79.6 \%)$ than part- or full-time employed $(20.4 \%)$ patients $(p \leq 0.05)$. Patients who had a mental health detection received referral more often $(42.9 \%)$ than patients without mental health detection $(5.1 \%)(p \leq 0.001)$. Patients with mental health detection were also more likely to self-report poor or fair health $(59.2 \%)$ than patients without detection $(22.4 \%),(p \leq 0.001)$. Other sociodemographic or healthrelated variables were not significantly associated with mental health detection. 


\section{Outcomes by intervention}

Analysis of the intervention and control groups shows that $58.7 \%$ of patients in the iCCAS group had a mental health discussion compared with $40.3 \%$ in the usual care group ( $p \leq$ 0.05 ) (Table 3). The intervention effect was significant on mental health discussion in the unadjusted analyses (odds ratio [OR] 2.11, p< 0.05). In the final GLMM, the effect of the iCCAS on mental health discussion remained significant (adjusted OR 2.2, $p=0.02$ ) while controlling for language, sex, education and employment (Table 3).

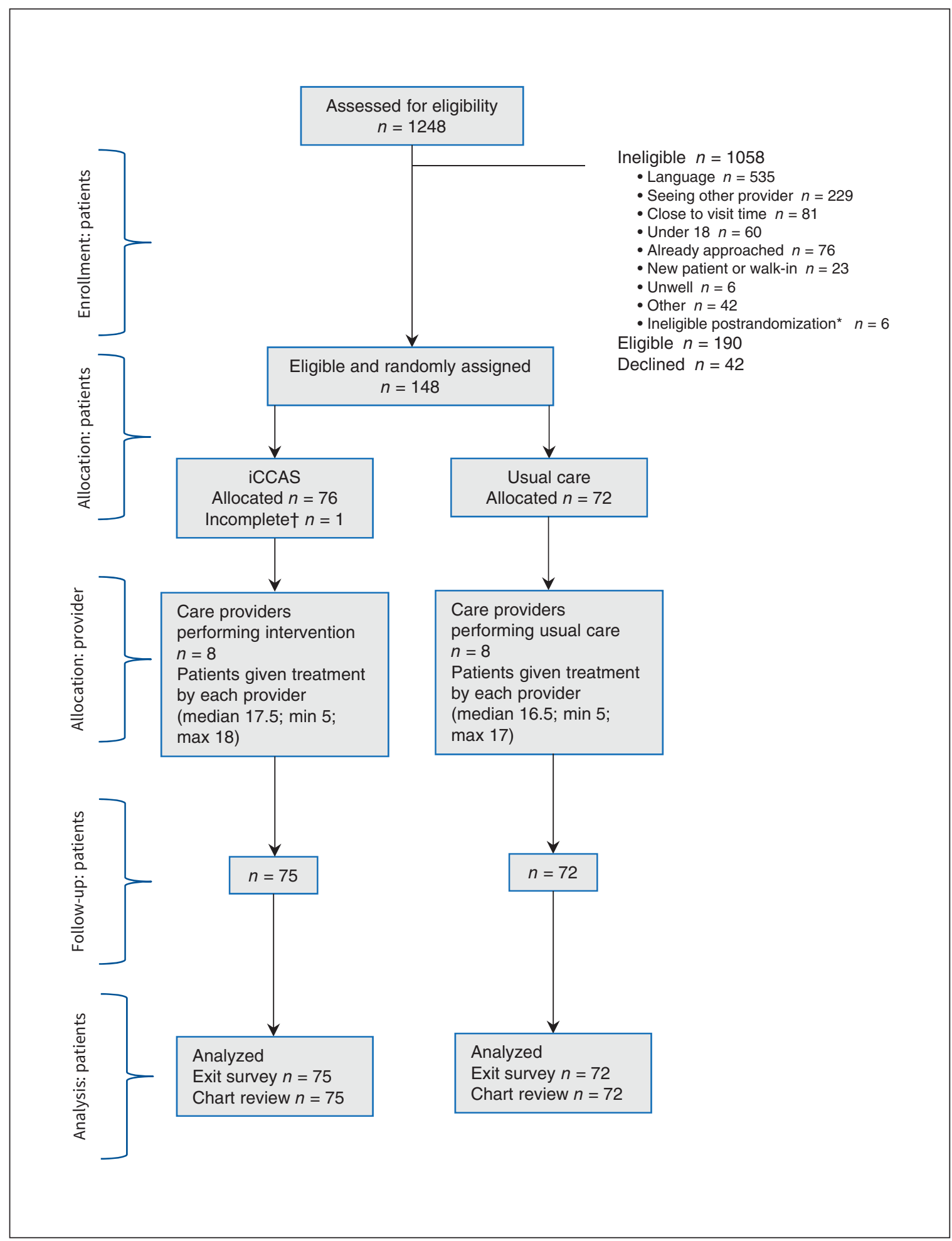

Figure 1: Study flow diagram. *Three patients already approached, 1 under age, 2 seeing other provider. †Patient felt unwell soon after consent and discontinued. 


\section{OPEN}

Research

In terms of mental health detection, $38.7 \%$ of patients in the iCCAS group had a clinical detection of mental health symptoms compared with $27.8 \%$ in the usual care group $(p>$ $0.05)$. The intervention effect was not significant on mental health detection in unadjusted analyses (OR 1.65, $p>0.05)$. In the final GLMM, the effect of iCCAS remained not signifi-

\begin{tabular}{|c|c|c|}
\hline Variable & $\begin{array}{c}\text { iCCAS, no. }(\%)^{*} \\
n=75\end{array}$ & $\begin{array}{l}\text { Usual care, no. }(\%)^{*} \\
n=72\end{array}$ \\
\hline Age, yr, mean \pm SD & $36.5 \pm 12.7$ & $37.5 \pm 12.2$ \\
\hline \multicolumn{3}{|l|}{ Sex } \\
\hline Male & $26(34.7)$ & $27(37.5)$ \\
\hline Female & $49(65.3)$ & $41(56.9)$ \\
\hline Transgender† & $0(0.0)$ & $4(5.6)$ \\
\hline \multicolumn{3}{|l|}{ Language } \\
\hline English & $59(78.7)$ & $56(77.8)$ \\
\hline Spanish & $16(21.3)$ & $16(22.2)$ \\
\hline \multicolumn{3}{|l|}{ Relationship status $\ddagger$} \\
\hline Married/common law & 37 (49.3) & $38(52.8)$ \\
\hline $\begin{array}{l}\text { Separated/divorced/ } \\
\text { widowed }\end{array}$ & $11(14.7)$ & $10(13.9)$ \\
\hline $\begin{array}{l}\text { Single, not in } \\
\text { relationship }\end{array}$ & $18(24.0)$ & $16(22.2)$ \\
\hline $\begin{array}{l}\text { Single, in } \\
\text { relationship }\end{array}$ & $10(13.3)$ & $9(12.5)$ \\
\hline Have children & $47(62.7)$ & $45(62.5)$ \\
\hline Immigrant & $74(98.7)$ & $70(97.2)$ \\
\hline \multicolumn{3}{|l|}{ Citizenship status } \\
\hline $\begin{array}{l}\text { Canadian citizen/ } \\
\text { permanent resident }\end{array}$ & $54(72.0)$ & $50(69.4)$ \\
\hline Other & $21(28.0)$ & $22(30.6)$ \\
\hline \multicolumn{3}{|l|}{ Years lived in Canada } \\
\hline Up to $5 \mathrm{rs}$ & $41(54.7)$ & $36(50.0)$ \\
\hline 5 or more yr & $34(45.3)$ & $36(50.0)$ \\
\hline \multicolumn{3}{|c|}{ Highest level of education } \\
\hline Up to grade 12 & $38(50.7)$ & $34(47.2)$ \\
\hline College or more & 37 (49.3) & $38(52.8)$ \\
\hline \multicolumn{3}{|l|}{ English reading/writing } \\
\hline Poor or fair & $19(25.3)$ & $18(25.0)$ \\
\hline Good or better & $56(74.7)$ & $54(75.0)$ \\
\hline \multicolumn{3}{|l|}{ Employment status } \\
\hline Full-time & $15(20.0)$ & $9(12.5)$ \\
\hline Part time & $11(14.7)$ & $16(22.2)$ \\
\hline Not employed & $49(65.3)$ & $47(65.3)$ \\
\hline \multicolumn{3}{|c|}{ Annual household income before taxes } \\
\hline$<20000$ & $48(64.0)$ & $46(63.9)$ \\
\hline $20000-30000$ & $12(16.0)$ & $18(25.0)$ \\
\hline $30000-40000$ & $8(10.7)$ & $2(2.8)$ \\
\hline $40000-60000$ & $2(2.7)$ & $4(5.6)$ \\
\hline$>60000$ & $5(6.7)$ & $2(2.8)$ \\
\hline \multicolumn{3}{|c|}{$\begin{array}{l}\text { Note: iCCAS = interactive computer-assisted client assessment survey. } \\
\text { *Unless otherwise specified. } \\
\text { †Subsequent analyses combined transgender with female (results were same on } \\
\text { combining with male). } \\
\text { łTotal does not sum up because patients were allowed to select more than } 1 \\
\text { response. }\end{array}$} \\
\hline
\end{tabular}

cant (adjusted OR 1.93, $p=0.08$ ), whereas the effect of language, sex, education and employment were significant on mental health detection.

\section{Interpretation}

Our study, with a multicultural sample of patients, shows that an interactive, user-friendly, health risk assessment tool for common mental disorders administered in English and Spanish by touch-screen tablet was effective in significantly increasing the frequency of patient discussions about mental health with their attending clinicians at the collaborating community health centre. In addition, the study clinicians detected mental health symptoms more frequently in the iCCAS intervention group than in the usual care group, although the difference was not quite significant in multivariate analysis. At the same time, the outcomes of mental health discussion and detection were significantly correlated, and patients with mental health symptom detection had a significantly higher frequency of mental health referral compared with those without detection.

Patients in the iCCAS group reported minimal technological difficulties, agreed with the tool's benefits and neither agree nor disagree with the barriers in relation to privacy or provider interaction. Overall, the results of this pilot trial sug-

Table 2: Patient health-related characteristics

\begin{tabular}{|c|c|c|}
\hline Variable & $\begin{array}{c}\text { iCCAS, no. (\%) } \\
n=75\end{array}$ & $\begin{array}{l}\text { Usual care, no. (\%) } \\
\qquad n=72\end{array}$ \\
\hline \multicolumn{3}{|l|}{ Self-rated health } \\
\hline Poor or fair & $27(36.0)$ & $24(33.3)$ \\
\hline $\begin{array}{l}\text { Good, very good or } \\
\text { excellent }\end{array}$ & $48(64.0)$ & $48(66.7)$ \\
\hline \multicolumn{3}{|l|}{ Purpose of visit } \\
\hline New problem & $21(28.0)$ & $12(16.7)$ \\
\hline $\begin{array}{l}\text { Routine physical } \\
\text { exam or follow-up }\end{array}$ & $54(72.0)$ & $60(83.3)$ \\
\hline $\begin{array}{l}\text { Follow-up suggested } \\
\text { in index visit) }\end{array}$ & $53(70.7)$ & $50(69.4)$ \\
\hline \multicolumn{3}{|l|}{ Internal referral provided } \\
\hline Mental health & $13(44.8)$ & $10(40.0)$ \\
\hline Other & $16(55.2)$ & $15(60.0)$ \\
\hline \multicolumn{3}{|l|}{ External referral provided } \\
\hline Maternal health & $2(9.1)$ & $1(4.5)$ \\
\hline Other & $20(90.9)$ & $21(95.5)$ \\
\hline \multicolumn{3}{|l|}{ Visit satisfaction } \\
\hline $\begin{array}{l}\text { Satisfied or very } \\
\text { satisfied }\end{array}$ & $59(78.7)$ & $61(84.7)$ \\
\hline Neutral & $7(9.3)$ & $6(8.3)$ \\
\hline $\begin{array}{l}\text { Dissatisfied or very } \\
\text { dissatisfied }\end{array}$ & $9(12.0)$ & $5(6.9)$ \\
\hline
\end{tabular}


gest that iCCAS positively facilitated the continuum of discussion, detection and referral for concerns about common mental disorders. A wider adoption of such preconsult tools in the community clinics serving vulnerable communities could be useful in reducing patient barriers to disclosing mental health concerns and clinician challenges in conducting symptom assessments, ${ }^{9-14}$ thereby facilitating diagnoses of common mental disorders in a timely manner. Future research with a larger sample and longitudinal arm is needed to enhance the generalizability of the reported results and to allow assessment of changes in mental health outcomes over time.

We were able to identify some systemic inequities in the

\begin{tabular}{|c|c|c|c|c|}
\hline Variable & \multicolumn{2}{|c|}{ No. (\%) of patients } & \multirow[t]{2}{*}{$\begin{array}{l}\text { Unadjusted OR } \\
\qquad(95 \% \mathrm{Cl})\end{array}$} & \multirow[t]{2}{*}{$\begin{array}{l}\text { Ajusted OR } \\
(95 \% \mathrm{Cl})\end{array}$} \\
\hline Mental health discussion & $\begin{array}{c}\text { Yes } \\
n=73\end{array}$ & $\begin{array}{c}\text { No } \\
n=74\end{array}$ & & \\
\hline \multicolumn{5}{|l|}{ Language } \\
\hline English & $63(86.3)$ & $52(70.3)$ & $2.67(1.15-6.18)$ & $2.80(1.15-6.85)^{*}$ \\
\hline Spanish† & $10(13.7)$ & $22(29.7)$ & & \\
\hline \multicolumn{5}{|l|}{ Sex } \\
\hline Female & $49(67.1)$ & $45(60.8)$ & $1.32(0.67-2.60)$ & $1.54(0.73-3.24)$ \\
\hline Male† & $23(32.9)$ & $29(39.2)$ & & \\
\hline \multicolumn{5}{|l|}{ Education } \\
\hline College or more & $38(52.1)$ & $37(50.0)$ & $1.09(0.57-2.09)$ & $1.32(0.65-2.66)$ \\
\hline Less than college & $35(47.9)$ & $37(50.0)$ & & \\
\hline \multicolumn{5}{|l|}{ Employed } \\
\hline Full-time & 9 (12.3) & $15(20.3)$ & $0.49(0.19-1.23)$ & $0.51(0.19-1.37)$ \\
\hline Part-time & $11(15.1)$ & $16(21.6)$ & $0.56(0.23-1.13)$ & $0.63(0.25-1.59)$ \\
\hline Not employed $†$ & $53(72.6)$ & $43(58.1)$ & & \\
\hline \multicolumn{5}{|l|}{ Group } \\
\hline iCCAS & $44(60.3)$ & $31(49.9)$ & $2.11(1.08-4.09)$ & $2.23(1.11-4.49)^{*}$ \\
\hline Usual care $†$ & $29(39.7)$ & $43(58.1)$ & & \\
\hline Mental health detection & $\begin{array}{c}\text { Yes } \\
n=49\end{array}$ & $\begin{array}{c}\text { No } \\
n=98\end{array}$ & & \\
\hline \multicolumn{5}{|l|}{ Language } \\
\hline English & $44(89.8)$ & $71(72.4)$ & 3.35 (1.19-9.42) & $3.02(1.01-9.03)^{*}$ \\
\hline Spanish† & $5(10.2)$ & $27(27.6)$ & & \\
\hline \multicolumn{5}{|l|}{ Sex } \\
\hline Female & $29(59.2)$ & $65(66.3)$ & $0.74(0.36-1.50)$ & $0.79(0.36-1.72)$ \\
\hline Male† & $20(40.8)$ & $33(33.7)$ & & \\
\hline \multicolumn{5}{|l|}{ Education } \\
\hline College or more & $30(61.2)$ & $45(45.9)$ & $1.86(0.92-3.76)$ & $2.31(1.08-4.96)^{*}$ \\
\hline Less than college & $19(38.8)$ & $53(54.1)$ & & \\
\hline \multicolumn{5}{|l|}{ Employed } \\
\hline Full-time & $3(6.1)$ & $21(21.4)$ & $0.21(0.06-0.76)$ & $0.17(0.04-0.66)^{*}$ \\
\hline Part-time & 7 (14.3) & $20(20.4)$ & $0.51(0.19-1.34)$ & $0.56(0.21-1.56)$ \\
\hline Not employed $†$ & $39(79.6)$ & $57(58.2)$ & & \\
\hline \multicolumn{5}{|l|}{ Group } \\
\hline iCCAS & $29(59.2)$ & $46(46.9)$ & $1.64(0.81-3.30)$ & $1.93(0.91-4.11)$ \\
\hline Usual care $†$ & $20(40.8)$ & $52(53.1)$ & & \\
\hline $\begin{array}{l}\text { Note: } \mathrm{Cl}=\text { confidence interval, iCC } \\
{ }^{*} p<0.05 . \\
\text { †Reference category. }\end{array}$ & interactive & r-assisted cli & ssessment survey, OF & = odds ratio. \\
\hline
\end{tabular}




\section{OPEN}

discussion of mental health problems and identification. Compared with Spanish-speaking patients (whose visits were mediated by a professional interpreter), patients who spoke English had more discussion and detection of mental health symptoms. This could reflect problems related to the presence of an interpreter or language barriers in spite of an interpreter. In addition, patients with college or higher education had higher rates of mental health symptom detection. This could represent differences in health literacy linked to educational attainment. ${ }^{38,39}$ Patients who were unemployed had a higher rate of clinician detection of mental health symptoms than their employed counterparts. This could be related to clinicians' vigilance to low income as a risk for common mental disorders, or decreased functionality of patients due to undetected and untreated mental illnesses. Collectively, these findings point toward a complex interaction between social conditions and access to mental health care for vulnerable ethnoracialized groups. ${ }^{40}$ There is an undeniable need for intersectoral approaches to address mental health inequities with attention to these social determinants.

Our study contributes to the area of computer-assisted health risk assessments for mental health that started in $1960 \mathrm{~s}^{41,42}$ and grew with the emergence of digital techonologies. Our study is not only specific to common mental disorders in primary care, but the interactive tool employs a "dual engagement" conceptual model by engaging patients and clinicians simultaneously and generating 2 types of individualized reports. This is a step forward in the field of computerassisted health risk assessments wherein the results of assessment reports are often generated automatically for clinicians only. Our search for such primary care, dual-engagement tools with a focus on depression identified only a handful of studies in the last decade. Most of these studies have used small convenience samples, ${ }^{24,43-45}$ with the exceptions of eCHAT, Promote Health and My Own Health Report (MOHR). ${ }^{22,46,47}$ Each of these studies, although valuable, either does not include a control group (eCHAT), is limited to academic settings with an above average income population (Promote Health) or is not widely available for use (MOHR). In this emerging area of patient-centred clinical informatics, the iCCAS study advances the field by recruiting an immigrant, refugee and ethnoracially diverse patient population from a community health centre and using rigorous randomized controlled design. Further developments could also draw from emerging work on patient portals (e.g., PatientSite) linked to electronic medical record systems. ${ }^{48,49}$

\section{Limitations}

We examined the intervention by collaborating with a single community health centre, which may limit generalizability. Further, availability of the tool only in English and Spanish allowed recruitment of a select group of patients at the clinic. The small sample size limited our ability to examine the intervention effect by sex, ethnicity or comorbidity. We could not collect data concerning nonresponders. The response rate of $78 \%$, however, enhances confidence in the reported results. Participating providers were potentially more likely to ask about mental health in the usual care group because of training for the study and non-masking of the intervention. However, because these biases diminish the group difference in outcomes, our estimates of the intervention effect are likely to be underestimates. Possible reasons for the lack of intervention effect on detection or case-finding warrants some discussion. On one side, our sample size was small; on the other, we collected data on the detection rates through chart reviews, which are a weak source of information because clinicians often take limited notes in charts. In addition, our review of charts was limited to the index visit, but case-finding for mental illnesses often requires multiple assessments, especially for patients from diverse cultural backgrounds and in need of interpreters to communicate with their clinicians. Further qualitative work (forthcoming) could assist in unpacking the underlying mechanisms through which the discussion rates improved.

\section{Conclusion}

Computer-assisted interactive and user-friendly health risk assessment tools in patients' languages of choice hold potential to improve timely discussion on common mental disorders among vulnerable immigrant communities served by the community health centre model. Such discussions are in turn anticipated to improve detection rates. Future research with larger samples and multiple primary care sites is needed to enhance the generalizability of the reported results.

\section{References}

1. Mathers CD, Loncar D. Projections of global mortality and burden of disease from 2002 to 2030. PLoS Med 2006;3:e442.

2. Pearson C, Janz T, Ali J. Mental and substance use disorders in Canada. Health at a glance. Cat no 82-624-X. Ottawa: Statistics Canada; 2013.

3. Olfson M, Shea S, Feder A, et al. Prevalence of anxiety, depression, and substance use disorders in an urban general medicine practice. Arch Fam Med 2000;9:876-83.

4. Magnus JH, Shankar A, Broussard DL. Self-report of depressive symptoms in African American and white women in primary care. $7 \mathrm{Natl}$ Med Assoc 2010;102:389-95.

5. Gilchrist G, Hegarty K, Chondros P, et al. Association between intimate partner violence, alcohol and depression in family practice. BMC Fam Pract 2010;11:72.

6. Arroll B, Goodyear-Smith F, Lloyd T. Depression in patients in an Auckland general practice. $N Z$ Med 7 2002;115:176-9.

7. Integrated models of primary care and mental health of substance use care in the community. Victoria: Government of British Columbia, Ministry of Health; 2012.

8. Changing directions, changing lives: the mental bealth strategy for Canada. Calgary: Mental Health Commission of Canada; 2012.

9. The buman face of mental bealth and mental illness in Canada 2006. Ottawa: Public Health Agency of Canada; 2006.

10. Hansson E, Tuck A, Lurie S; Task Group of the Services Systems Advisory Committee, Mental Health Commission of Canada. Improving mental bealth services for immigrant, refugee, ethno-cultural and racialized groups: issues and options for service improvement. Calgary: Mental Health Commission of Canada; 2010. Available: www.mentalhealthcommission.ca/sites/default/files/Diversity_Issues_Options_Report_ENG_0_1.pdf (accessed 2016 Apr. 15).

11. Tiwari SK, Wong J. Ethnic differences in mental health service use among White, Chinese, South Asian and South East Asian populations living in Canada. Soc Psychiatry Psychiatr Epidemiol 2008;43:866-71.

12. Kirmayer LJ, Narasiah L, Munoz M, et al.; Canadian Collaboration for Immigrant and Refugee Health (CCIRH). Common mental health problems in immigrants and refugees: general approach in primary care. CMAJ 2011;183:E959-67.

13. Parikh SV, Lin E, Lesage AD. Mental health treatment in Ontario: selected comparisons between the primary care and specialty sectors. Can $\mathcal{F}$ Psychiatry 1997;42:929-34.

14. Community health centres. Toronto: Association of Ontario Health Centers. Available: www.aohc.org/community-health-centres (accessed 2016 Apr. 15).

15. Glazier RH, Zagorski BM, Rayner J. Comparison of primary care models in 
Ontario: by demographics, case mix and emergency department use 2008/09 to 2009/10. Toronto: Institute for Clinical Evaluative Sciences; 2012.

16. Russell GM, Dahrouge S, Hogg W, et al. Managing chronic disease in Ontario primary care: the impact of organizational factors. Ann Fam Med 2009;7:309-18.

17. Dahrouge S, Hogg W, Tuna $M$, et al. Age equity in different models of primary care practice in Ontario. Can Fam Physician 2011;57:1300-9.

18. Liddy C, Singh J, Hogg W, et al. Comparison of primary care models in the prevention of cardiovascular disease - a cross sectional study. BMC Fam Pract 2011;12:114.

19. E-mental health in Canada: transforming the mental bealth system using technology. Ottawa: Mental Health Commission of Canada; 2014.

20. Gibbons CM. eHealth solutions for healthcare disparities. New York: Springer; 2008.

21. Ahmad F, Hogg-Johnson S, Stewart D, et al. Computer-assisted screening for intimate partner violence and control: A randomized trial. Ann Intern Med 2009;151:93-102.

22. Ahmad F, Norman C, O'Campo P. What is needed to implement a computerassisted psychosocial risk assessment tool? An exploratory concept mapping study. BMC Med Inform Decis Mak 2013;12:e11.

23. Ahmad F, Shakya Y, Li J, et al. A pilot with computer-assisted psychosocial risk-assessment for refugees. BMC Med Inform Decis Mak 2012;12:71.

24. Boutron I, Moher D, Altman D, et al. CONSORT Group. Extending the CONSORT statement to randomized trials of nonphramacologic treatment: explanation and elaboration. Ann Intern Med 2008;148:295-309.

25. Immigration and ethnocultural diversity in Canada. National Housebold Survey, 2011. Cat no 99-010-X2011001. Ottawa: Statistics Canada; 2013

26. Spitzer RL, Kroenke K, Williams JBW. Validation and utility of a self-report version of PRIME-MD: The PHQ primary care study. fAMA 1999;282: 1737-44.

27. Spitzer RL, Kroenke K, Williams JBW, et al. A brief measure for assessing generalized anxiety disorder: the GAD-7. Arch Intern Med 2006;166:1092-7.

28. Prins A, Ouimette P, Kimerling R, et al. The primary care PTSD screen (PC-PTSD): Development and operating characteristics. Prim Care Psychiatry 2003;9:8-14.

29. Ewing JA. Detecting alcoholism. The CAGE questionnaire. $7 A M A$ 1984;252: 1905-7.

30. Ahmad F, Shakya Y, Ginsburg L, et al. Burden of common mental disorders in a community health centre sample. Can Fam Physician 2016;62:e758-66.

31. Ferrari M, Ahmad F, Shakya Y, et al. Computer-assisted client assessment survey for mental health: patient and health provider perspectives. $B M C$ Health Serv Res 2016;16:516.

32. Doig GS, Simpson F. Randomization and allocation concealment: a practical guide for researchers. 7 Crit Care 2005;20:187-91.

33. Skinner HA. Early identification of addictive behaviors using computerized life-style assessment. In: Baer JS, Marlatt GA, McMahon RJ, editors. Addictive behaviors across the lifespan: Prevention, treatment and policy issues. Newbury Park (CA): Sage; 1993:89-110.

34. Ahmad F, Hogg-Johnson S, Skinner HA. Assessing patient attitudes to computerized screening in primary care: psychometric properties of the computerized lifestyle assessment scale. 7 Med Internet Res 2008;10:e11.

35. Buxton J, White M, Osoba D. Patients' experiences using a computerized program with a touch-sensitive video monitor for the assessment of healthrelated quality of life. Qual Life Res 1998;7:513-9.

36. Allenby A, Matthews J, Beresford J, et al. The application of computer touchscreen technology in screening for psychosocial distress in an ambulatory oncology setting. Eur 7 Cancer Care (Engl) 2002;11:245-53.

37. Fergusson D, Aaron SD, Guyatt G, et al. Post-randomisation exclusions: the intention to treat principle and excluding patients from analysis. BMF 2002; $325: 652-4$.
38. Williams MV, Davis T, Parker RM, et al. The role of health literacy in patient-physician communication. Fam Med 2002;34:383-9.

39. Achieving health equity: from root causes to fair outcomes. Geneva: Commission on Social Determinants of Health, World Health Organisation; 2007.

40. Kim I-H, Carrasco C, Muntaner C, et al. Ethnicity and postmigration health trajectory in new immigrants to Canada. Am $\mathcal{F}$ Public Health 2013;103: e96-104.

41. Slack WV, Hicks GP, Reed CE, et al. A computer-based medical-history system. N Engl 7 Med 1966;274:194-8.

42. Maultsby MC, Slack WV. A computer-based psychiatry history system. Arch Gen Psychiatry 1971;25:570-2.

43. Leung SF, French $\mathrm{P}$, Chui C, et al. Computerized mental health assessment in integrative health clinic: A cross-sectional study using structured interview. Int 7 Ment Health Nurs 2007;16:441-6.

44. Shakeshaft A, Fawcett J, Mattick RP, et al. Patient-driven computers in primary care: Their use and feasibility. Health Educ 2006;106:400-11.

45. Farrell SP, Mahone IH, Zerull LM. Electronic screening for mental health in rural primary care: implementation. Issues Ment Health Nurs 2009;30:165-73.

46. Goodyear-Smith F, Warren J, Bojic M, et al. eCHAT for lifestyle and mental health screening in primary care. Ann Fam Med 2013;11:460-6.

47. Krist AH, Phillips SM, Sabo RT, et al.; MOHR Study Group. Adoption, reach, implementation, and maintenance of a behavioral and mental health assessment in primary care. Ann Fam Med 2014;12:525-33.

48. Slack WV, Kowaloff HB, Davis RB, et al. Evaluation of computer-based medical histories taken by patients at home. 7 Am Med Inform Assoc 2012; 19:545-8.

49. Bajracharya AS, Crotty BH, Kowaloff HB, et al. Improving health care proxy documentation using a web-based interview through a patient portal. $7 \mathrm{Am}$ Med Inform Assoc 2016;23:580-7.

Affiliations: School of Health Policy and Management (Ahmad, Ginsburg, Dinca-Panaitescu), York University; Biostatistics Division (Lou), Dalla Lana School of Public Health, University of Toronto; Access Alliance Multicultural Health and Community Services (Shakya, Ledwos); School of Administrative Studies (Ng), York University; Women's College Hospital (Rashid); Department of Family and Community Medicine (Rashid), University of Toronto; Centre for Addiction and Mental Health (McKenzie); The Wellesley Institute (McKenzie), Toronto, Ont.

Contributors: All authors contributed in the study design. Farah Ahmad, Yogendra Shakya and Kwame McKenzie developed the study protocol, training and materials. Farah Ahmad supervised data collection. Farah Ahmad, Wendy Lou and Peggy Ng conducted analysis and the results were interpreted by all authors. Farah Ahmad developed the first draft of manuscript, which was critically reviewed by all authors and approved for submission. All of the authors approved the final version to be published and agreed to act as guarantors of the results.

Funding: This study was funded by a Canadian Institutes of Health Research (CIHR) eHealth Catalyst Grant (FRN \# 126526). During this work Dr. Ahmad's time was partly supported by the CIHR New Investigator Award. The funding bodies had no role in the study design, data collection, analysis, interpretation, and manuscript preparation or submission.

Supplemental information: For reviewer comments and the original submission of this manuscript, please see www.cmajopen.ca/content/5/1/ E190/suppl/DC1 